\title{
Пинг-понг-эффект трансатлантических биоинвазий (на примере южноамериканской томатной моли)
}

\section{К.А. Перевертин, В.И. Леунов, Р.А. Багров, Т.А. Васильев}

Феномен «Колумбова обмена» (Columbian exchange), начавшийся около 500 лет назад, далеко не закончен, что подтверждается происходящими в Евразии эпифитотиями, вызываемыми вредными организмами американского происхождения. Цель исследования - проанализировать закономерности межконтинентальных инвазий вредоносных организмов, включая южноамериканскую томатную моль. В исследованиях использовали стандартные методы мониторинга насекомых фитофагов, метод аппроксимации по опытным данным онтогенеза стадий моли в зависимости от температуры в вегетационно-климатических шкафах. Представлена информация о распространении южноамериканской томатной моли в Старом Свете, обсуждены теоретические аспекты развития межконтинентальных инвазий, выделены фазы эволюции отношений «хозяин-паразит» (фоновая, латентная, интенсивная, феномен межконтинентальной стресс-биоинвазии). Приведены примеры межконтинентальных биоинвазий вредных организмов, детерминировавших социально значимые эпифитотические последствия (вспышки массового размножения/развития). Представлены термодетерминантные аспекты онтогенеза томатной минирующей моли. На основе экспериментальных данных построена математическая модель онтогенеза Tuta absoluta в зависимости от температуры. Применение модели для оценочных прогнозов термоадаптации вредителя с использованием данных метеостанций показало возможность развития томатной моли в Московской области минимально в двух генерациях. Приведен пример картограммы прогноза числа генераций Tuta absoluta для Московской области. По результатам оценочного моделирования (с использованием данных районных метеостанций за 2017 год) в зоне наибольшего риска акклиматизации вредного организма были Коломенский и Каширский административные районы. Дана информация о нижних термолимитах акклиматизации объектов карантинных биоинвазий для РФ. Механизм трансатлантических биоинвазий определен нами как «пинг-понгэффект». Это феномен инверсионной неоднократности межконтинентальных биоинвазий в рамках Колумбового обмена описывает биоинвазию Tuta absoluta, прямая аналогия которой - трансатлантическая эпифитотия глободероза картофеля. Схема выглядит следующим образом: перенос растенияхозяина из Нового света в Старый, его селективное улучшение, затем обратный перенос улучшенных форм в Новый свет, где они поражаются коэволюционно связанным вредным организмом - и перенос уже вредного организма в Старый свет с последующей эпифитотией.

Ключевые слова: Tuta absoluta, Колумбов обмен, онтогенез, математическая модель, термодаптация, картограмма.

овременное аграрное землепользование Евразии трудно представить без картофеля («второй хлеб»), томатов (мировой лидер среди овощей по производству) и кукурузы (базовая кормовая культура), имеющих американское происхождение. Впрочем, и агробиоценозы американского континента также трудно представить без колосовых зерновых и, например, яблок и свеклы. Процесс обоюдных транс- атлантических биоинвазий, начавшийся полтысячелетия назад, получил от историка Артура Кросби (А. Crosby, 1972), прижившееся название Колумбового обмена (Columbian exchange). Разумеется, пик обмена радикально трансформировавшего биоценозы как Старого, так и Нового света, пришелся еще на начало Нового времени. Казалось бы, за 500 лет при активнейшем взаимообмене (в том числе и биоинвазиями) меж- ду Старым и Новым светом должно быть достигнуто состояние некоего равновесия, однако практика именно последнего времени убеждает в обратном. Яркий пример - обсуждаемая в данной работе межконтинентальная инвазия южноамериканской томатной моли (томатной минирующей моли) Tuta absoluta (Meirik, 1917, Povolny, 1994), начавшаяся с катастрофической вспышки численности в Испании в 2006 году и в кратчайшее время распространившаяся по Евразии и Африке.

Цель исследования - проанализировать закономерности межконтинентальных инвазий вредоносных организмов, включая южноамериканскую томатную моль.

Условия, материалы и методика исследований. В исследованиях использовали стандартные методы мониторинга насекомых фитофагов, метод аппроксимации по опытным данным онтогенеза стадий моли в зависимости от температуры в вегетационно-климатических шкафах $[1,2,3,4]$.

Результаты и обсуждение. В аспекте отношений «хозяин-паразит», биоинвазионный фактор Колумбового обмена зачастую не сводится исключительно к однократному трафику - трансатлантическому переносу растений-хозяев и (или) вредных организмов (переносов может быть больше одного по принципу «теннисного мяча» - феномен, который мы предлагаем называть эффект пинг-понга или пинг-понг-эффект). Он также включает в себя антропогенно детерминированное ускорение адаптационно-эволюционных процессов - селекцию устойчивых сортов, трансформацию биоты агроландшафтов за счет коррекции биоразнообразия и т.д. Это происходит на обоих берегах Атлантики.

Массовые размножения фитофагов нехарактерны для дикорастущих предков томата в естественных биоценозах западных склонов Анд, с которыми Tuta absoluta тысячелетия- 
ми была связана трофически и топически. Напротив, первые отмеченные масштабные вспышки численности вредителей в государствах Южной Америки (в том числе и к востоку от Анд) относятся к периоду интенсификации возделывания томатов в шестидесятые-семидесятые годы XX века, причем именно на высокопродуктивных линиях сортов томатов, ввезенных из Европы.

Отметим и нестрогую категоричность фактора «неготовности социума» к трансатлантическим биоинвазиям. Например, первая евроконтинентальная инвазия колорадского картофельного жука началась в 1877 году в Германии (Саксония). Другая популяция была обнаружена год спустя в Царстве Польском (Российская Империя) [5]. Эти популяции были успешно искоренены вскоре после обнаружения - с привлечением к радикальным карантинным мероприятиям даже воинских подразделений, использованием «огненных рвов» и т.п. [6]. Необратимая биоинвазия колорадского жука в Европу произошла на 40 лет позже, в 1917 году.

И, напротив, при обсуждаемой интродукции томатной моли в 2006 году даже высочайший современный (глобальный) уровень информационнотехнологического обеспечения карантинных мероприятий не смог воспрепятствовать быстрому распространению вредителя по Средиземноморью, Западной и Центральной Европе. Единственное, чего удалось избежать сопредельным странам - это повторения катастрофичности испанского сценария.

Распространение южноамериканской томатной моли в Старом Свете

Первое массовое размножение Tuta absoluta на томате при ее заносе в Европу на юге Испании в 2006 году носило беспрецедентно масштабный характер и было признано катастрофическим. Этому способствовали сложившиеся погодные условия оптимальные диапазоны температур, влажности и, в немалой степени, устойчивые сильные ветры в весенне-летний период. Среди значимых антропогенных факторов, способствовавших распространению фитофага наряду с интенсивностью грузопотоков, - специфика логистики плодоовощной продукции с использованием многоразовой тары.

Краткий хронологический обзор распространения Tuta absoluta иллюстрирует выраженную географи- ческую агрессивность вида-иммигранта в Старом Свете:

Север Испании и о. Ибица 2007 год, Португалия - 2008 год, Италия - 2008 год, Франция 2008 год, Алжир, Марокко, Тунис 2008 год, Великобритания - 2009 год (причем в июне вредитель был обнаружен на ввозимой таре и плодах, а уже в августе зарегистрирован в защищенном грунте). В том же 2009 году моль регистрируется в Германии, Чехии, Нидерландах, Беларуси, Украине и параллельно продолжает распространение в Средиземноморье - Мальта, Ливия, Албания, Греция, Израиль, Иордания, Турция, Сирия, Африка к югу от Сахары. В 2016 году фитофаг зарегистрирован в Нигерии и Замбии, куда вредитель был предположительно занесен из Сенегала. С 2011 года поступают сообщения о регистрации южноамериканской томатной моли в Казахстане. В 2015 году отмечено размножение в тепличных комбинатах Актюбинской, КзылОрдинской, Жамбылской, ЮжноКазахстанской областей, а для последней с 2017 года констатирована акклиматизация в открытом грунте.

В России первое сообщение о минирующей моли впервые поступило в 2009 году от специалистов ФГБУ Калининградской межобластной ветеринарной лаборатории. Изолированный Балтийский анклав не репрезентативен для РФ, но уже в ноябре 2010 года вредитель был выявлен в защищенных грунтах Краснодарского края, а в 2011 года в Адыгее, Дагестане. Вредитель внесен в Перечень карантинных объектов (Приказ Минсельхоза РФ № 501 от 05.12. 2014 года).

Эпизоды регистрации по РФ имеют достаточно широкую географию. Например, в 2015 году вид регистрируется в Крыму (Сакский район), 16 июня 2016 года - в Камызякском районе Астраханской области, 3 июня 2016 года управлением Россельхознадзора по Алтайскому краю предписано уничтожение партии томатов из Узбекистана в связи с обнаружением в ней Tuta absoluta.

C 2011 по 2014 годы томатную минирующую моль регистрировали на импортной плодоовощной продукции и таре в партиях, поступивших в оптовую и розничную торговлю Москвы [7, 8]. Мониторинг распространения Tuta absoluta ведется Всероссийским НИИ карантина растений. В определенной мере отражением не только распростране- ния и акклиматизации, но и локальных проявлений вредоносности служит современное содержание интернет-сайтов товаропроизводителей овощной продукции, где кроме популярных описаний южноамериканской томатной моли и обмена опытом присутствуют коммерческие предложения с доставкой по РФ средств борьбы, в частности, клейких ловушек.

Теоретические аспекты развития межконтинентальных инвазий

«Одномерное», вернее, «однонаправленное» понимание межконтинентального переноса вредного организма вслед за растением-хозяином не учитывает механизмов пинг-понгэффекта - феномена инверсивной неоднократности межконтинентальных биоинвазий. Например, агент необратимого паразитарного загрязнения почв - золотистая картофельная нематода Globodera rostochiensis, коэволюционно связанная с дикими предками картофеля в Андах, последовательно, с послевоенного по настоящее время, регистрируется теперь уже в семидесяти регионах РФ, где наносит существенный ущерб. Однако если в Европе впервые глободероз отмечен в Германии в 1913 году, то в США - в 1941 году, в Канаде в шестидесятых годах XX века, в Мексике в семидесятых годах (схема распространения межконтинентальной паразитарной биоинвазии: Южная АмерикаЕвропа-Северная Америка).

Можно выделить следующие фазы эволюции отношений «хозяин-паразит»:

1) фоновая фаза вредоносности базовая ситуация. Тысячелетиями вредный организм, коэволюционно связанный с растением-хозяином, не наносит значимого вреда, как правило, в очагах происхождения культуры;

2) латентная фаза вредоносности - распространение вредного организма за пределы очага происхождения с возможным расширением круга растений-хозяев;

3) интенсивная фаза вредоносности - целевое возделывание культуры растения-хозяина на фоне интенсификации земледелия, приводящее к резкому возрастанию вредоносности;

4) фаза (феномен) межконтинентальной стресс-биоинвазии - трансокеанская интродукция вредного организма в условиях изобилия хозяев, не имеющих (утративших) иммунитет, в благоприятном климате, при отсутствии (низкой активности) при- 


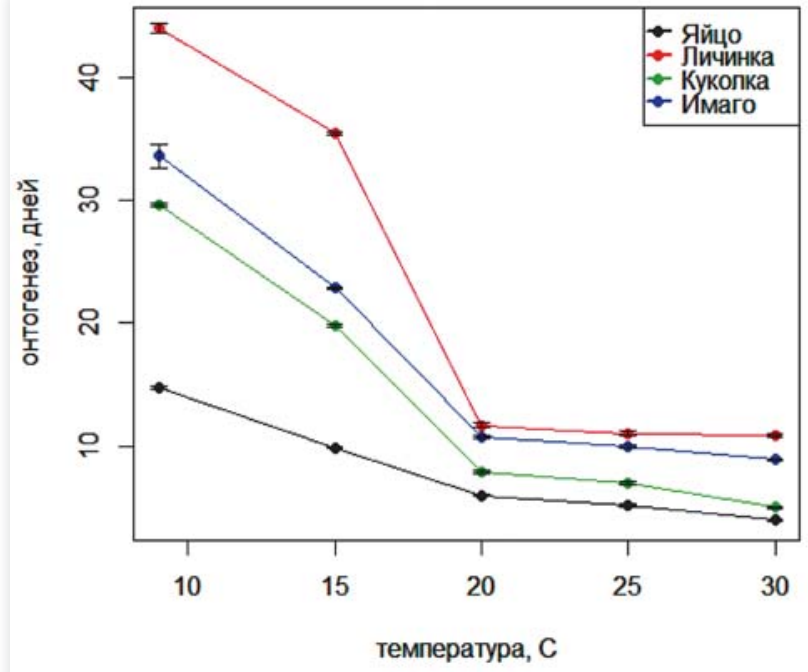

Pис. 1. Аппроксимация зависимости онтогенеза Tuta absoluta от температуры по экспериментальным данным

родных антагонистов приводящая к катастрофическим вспышкам размножения, чему также чему в немалой степени способствуют процессы глобализации природопользования и прогрессирующие климатические изменения [9].

В таблицу нами сведены характеристики некоторых вспышек размножения, определивших значимый в землепользовании социально-экономический резонанс (катастрофические последствия) инициированные межконтинентальной интродукцией. Однако, несмотря на указан- ную общность, все они (строки таблицы) имеют существенные различия, которые отражены в предлагаемой классификационной мнемосхематической кодировке (столбец 4 таблицы).

Направлени е стрелки слева направо означает трансатлантический трафик биоинвазии из Нового света в Старый, и, соответственно, наоборот.

Краткое содержательное описание строк таблицы, с учетом мнемокодов в столбце 4:

Свекловичная цистообразующая нематода (мнемокод: < $<<)$

В Средиземноморье листовая форма растения-хозяина - свеклы Beta vulgaris описана еще античным автором Теофрастом, который, конечно, не мог обратить внимание на микроскопических паразитов, имеющих фоновую вредоносность. В средневековье свеклу вводили в культуру на территории Европы, в том числе к северу от Альп, где к XVIII веку из кормовых форм выделилась сахароносная линия свеклы. Начало перехода от латентной к интенсивной вредоносности возбудителя гетеродероза (в данном редком случае) определяется хронологически точно - с указа Наполеона от 27 марта 1810 года об организации в условиях континентальной блокады свекловичного сахароварения, как альтернативы импорту тростникового (колониального) сахара. К середине XIX века в государствах Германии (не имевших колоний) наблюдается феномен свеклоутомления почв (Zuckerrubenmudickeit) причина которого - гетеродероз - установлена Ю. Кюном в 1859 году, а уже в 1895 эпифитотия констатирована в штате Юта, США, где до сих пор (например, в штате Калифорния), проблема настолько хозяйственно значима, что применяется даже давно не практикуемая в РФ фумигация почв.

\section{$>>1$}

Колорадский жук (мнемокод $><$

Схема Колумбового обмена достаточно специфична. Картофель, ввезенный в Европу из Южной Америки, прошел многолетнее введение в культуру, затем именно сорта европейской селекции широко возделывали в Северной Америке, где жук, имевший фоновую вредоносность на пасленовых, перешел на картофель. Начиная с эпифитотии 1859 года, от давшего ему название штата Колорадо к 1876 году жук достиг восточного побережья США и Канады. В 1877 году впервые зарегистрирован в Саксонии, но очаг был уничтожен (см. выше), и только

\begin{tabular}{|c|c|c|c|c|c|}
\hline \multicolumn{3}{|c|}{ Вредоносность } & \multirow{2}{*}{$\begin{array}{c}\text { «Колумбов обмен» } \\
\text { Новый свет//Старый } \\
\text { свет } \\
\text { Хозяин; }>,< \\
\text { Паразит; }>>,<<\end{array}$} & \multirow[b]{2}{*}{$\begin{array}{c}\text { Год } \\
\text { межконтинентальной } \\
\text { биоинвазии }\end{array}$} & \multirow{2}{*}{$\begin{array}{c}\text { Год первой } \\
\text { регистрации } \\
\text { на территории } \\
\text { Российской } \\
\text { Империи, СССР, РФ }\end{array}$} \\
\hline фоновая & латентная & интенсивная & & & \\
\hline \multicolumn{6}{|c|}{ Свекловичная цистообразующая нематода Heterodera schachtii } \\
\hline $\begin{array}{l}\text { Средиземноморье, } \\
\text { с XVIII века - Европа }\end{array}$ & $\begin{array}{c}\text { с } 1810 \text { года - } \\
\text { Наполеоновская } \\
\text { Европа }\end{array}$ & $\begin{array}{c}\text { Около } 1859 \text { - } \\
\text { Германия (Галле) }\end{array}$ & $\begin{array}{l}< \\
<<\end{array}$ & $\begin{array}{c}1895- \\
\text { США, Юта }\end{array}$ & $\begin{array}{c}1895 \text { - } \\
\text { Варшавская губерния, } \\
\text { сегодня - время Чер- } \\
\text { ноземье РФ }\end{array}$ \\
\hline \multicolumn{6}{|c|}{ Колорадский жук Leptinotarsa decemlineata } \\
\hline $\begin{array}{l}\text { Северо-восток Мекси- } \\
\text { ки (Сонорский регион) }\end{array}$ & $\begin{array}{c}1824- \\
\text { Скалистые горы, США }\end{array}$ & $\begin{array}{c}\text { 1855-1859 - } \\
\text { Небраска -Колорадо, } \\
\text { США }\end{array}$ & $\begin{array}{l}> \\
< \\
>>\end{array}$ & $\begin{array}{c}1877- \\
\text { Лейпциг, Германия } \\
\text { (очаг уничтожен); } \\
1917- \\
\text { Бордо, Франция }\end{array}$ & $\begin{array}{c}1949 \text { - } \\
\text { Львовская обл. } \\
\text { Сегодня - во многих } \\
\text { регионах картофеле- } \\
\text { водства РФ }\end{array}$ \\
\hline \multicolumn{6}{|c|}{ Томатная минирующая моль Tuta absoluta } \\
\hline $\begin{array}{c}\text { Западный склон Анд, } \\
\text { Перу }\end{array}$ & $\begin{array}{c}1960-\mathrm{e}- \\
\text { Колумбия, } \\
\text { Чили, } \\
\text { Аргентина }\end{array}$ & $\begin{array}{c}\text { 1970-е - } \\
\text { вся Южная Америка }\end{array}$ & $\begin{array}{l}> \\
< \\
>>\end{array}$ & $\begin{array}{c}2006- \\
\text { Испания, } \\
\text { Сегодня - Евразия, } \\
\text { Африка }\end{array}$ & $\begin{array}{c}2009- \\
\text { Калининградская обл., } \\
2010- \\
\text { Краснодарский край } \\
\text { 2011-г.Москва }\end{array}$ \\
\hline
\end{tabular}


в 1917 году занос вредителя с американским экспедиционным корпусом через порт Бордо, Франция привел к его широкому распространению по Евразии.

Южноамериканская томатная моль (мнемокод $><>>$ ).

K моменту первоописания в 1917 году в Перу моль имела фоновую вредоносность. Эпифитотии начались с интенсификации возделывания томатов европейской селекции, возвращенных в Южную Америку. В шестидесятые годы XX века на фоне широкого распространения в Перу и Чили биоинвазия была перенесена через Анды и зарегистрирована в Колумбии и Аргентине. Дольше всех на континенте оставалась свободной от этообщение относится к 1979 году (на плантациях побережья южного штата Парана), но уже в следующем году поступают сообщения со всей страны. Трансатлантический занос в Европу (Испания, 2006 год) - один из последних впечатляющих эксцессов Колумбового обмена.

Отметим, что совпадение мнемокодов для колорадского жука и расго фитофага Бразилия - первое со-

сматриваемой томатной моли - не означает принципиальной идентичности биоинвазий, в первую очередь из-за кардинальных эволюционных различий трофических и топических связей вида насекомого с видом растения-хозяина.

Термодетерминантные аспекты онтогенеза томатной минирующей моли

У Tuta absoluta цикл развития, лишен диапаузы (то есть непрерывен). Продолжительность стадий развития изменяется в зависимости от условий окружающей среды, в частности, от температуры. В Иордании число полных генераций может составлять до десяти в год и меняться при переходе с севера на юг. В теплице Tuta absoluta активна на протяжении большей части года с весны до осени. В холодные месяцы года преобладают куколки. Продолжительность жизни яйца, личинки и куколки уменьшается с повышением средней температуры, причем более выраженное снижение отмечается между пограничными поколениями в холодную погоду, и другое ослабление в жаркое время года. Нижний температурный порог для стадии яйца, ли-

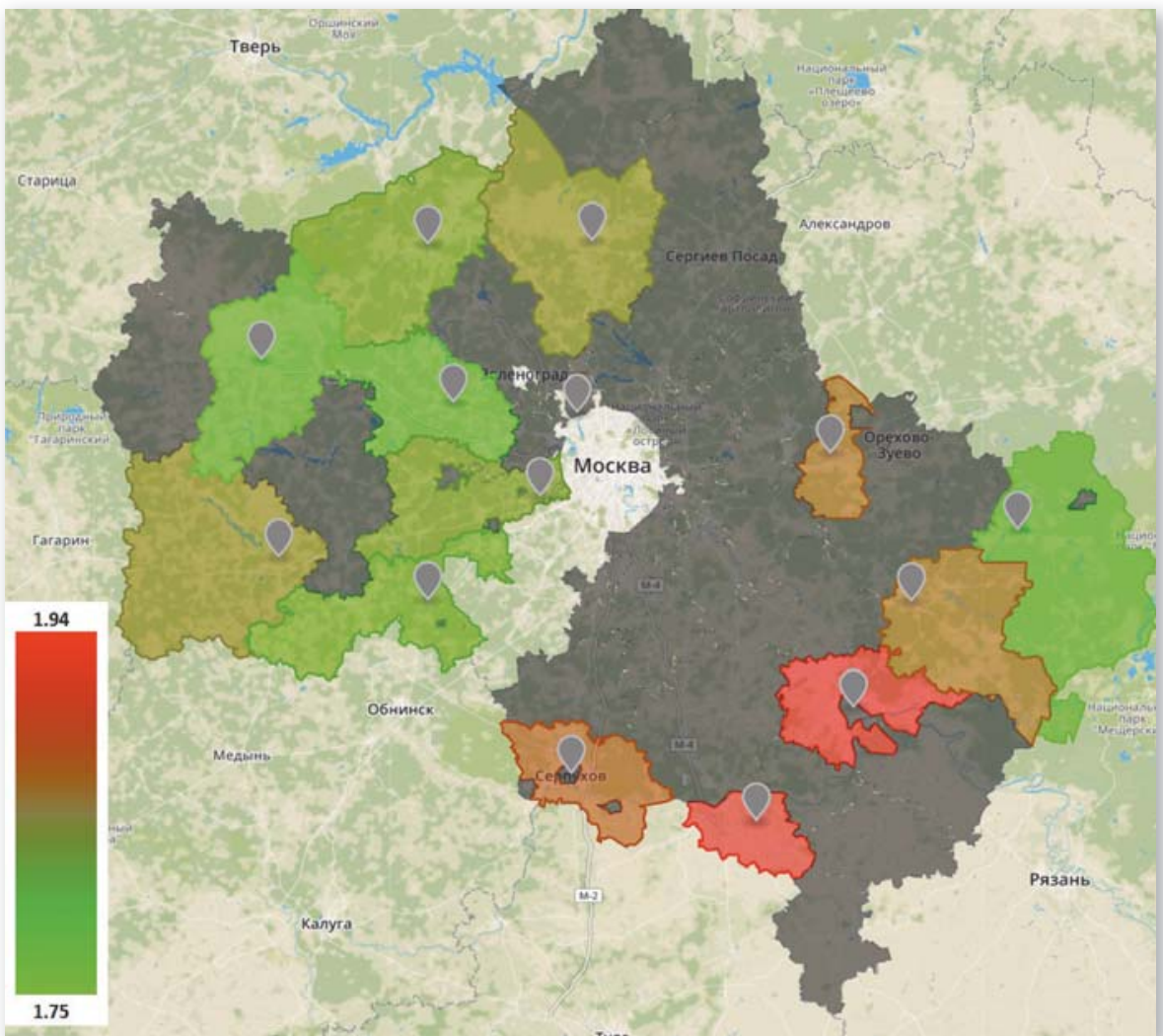

Рис. 2. Картограмма прогноза числа генераций Tuta absoluta для некоторых районов Московской области. По результатам оценочного моделирования (с использованием данных районных метеостанций за 2017 год) в зоне наибольшего риска акклиматизации вредного организма (красный фон) - Коломенский и Каширский административные районы чинки и куколки составляет 9,5 и $8{ }^{\circ} \mathrm{C}$ соответственно.

Модель оценки минимального числа генераций Tuta absoluta

Нами построена прогностическая модель для оценки последствий акклиматизации южноамериканской минирующей моли с расчетом такого важнейшего показателя, как минимальное число полных генераций вредителя. Использованы опытные данные по онтогенезу стадий моли в зависимости от температуры в вегетационно-климатических шкафах [3].

Ряд допущений - игнорирование параметров влажности, характеристик питания, выживаемости особей на разных стадиях онтогенеза, которые не являются критическими для требуемой адекватности модели, учитывая ее оценочный характер.

Система уравнений решалась для полного цикла развития с использованием температурных данных районных метеостанций в течение вегетационного периода 2017 года для Московской области (15.0501.09). Полученное число циклов (близкое к двум генерациям) отражено на картограмме (рис. 2).

К вопросу о нижних термолимитах акклиматизации объектов карантинных биоинвазий для РФ

Важный (ключевой) вопрос акклиматизации тропических (в т.ч. межконтинентальных) биоинвазионных видов на территории РФ - возможность выживания таких организмов в суровый зимний период. Однако, широко применявшийся еще в дореволюционной России радикальный метод «промораживания» изб, как эффективное средство локальной девастации популяций тараканов, не сделал территорию свободной от Blatella germanica.

Южная галловая нематода Meloydogine incognita, для которой, даже в самой защищенной стадии яйца, летальна любая отрицательная температура, многие десятилетия наносит серьезнейший ущерб томатам защищенного грунта на территории России.

Термоадаптация колорадского жука выражается в зимовке на глубине 30-50 см в самых климатически-суровых зонах картофелеводства.

Низкий уровень культуры карантинных мер особенно в личных подсобных хозяйствах: хранение инвентаря и тары в непромораживаемых помещениях, сбор растительных остатков в компостные ямы, являющихся, как известно, термобиореакторами 
и т.п. делают необратимую акклиматизацию томатной моли значимой угрозой по всей зоне выращивания томатов в открытом грунте РФ [8]

В формате наблюдаемого глобального потепления актуальна констатация повышения индекса биоклиматического потенциала сельхозугодий РФ [9]. Это предполагает не только возможность акклиматизации в РФ южноамериканской томатной моли, но и повышение вероятности риска эпифитотий.

\section{Выводы}

Обзор распространения межконтинентальной биоинвазии Южноамериканской томатной моли по Евразии показывает безусловную опасность данного вредного организма для овощеводства РФ.

Введенное нами понятие «пингпонг эффекта», как феномена инверсионной неоднократности межконтинентальных биоинвазий в русле Колумбового обмена в полной мере относится к рассматриваемой проблеме Tuta absoluta, прямой аналогией для которой является трансатлантическая эпифитотия глободероза картофеля. Схема выглядит следующим образом: перенос растения-хозяина из Нового света в Старый, его селективное улучшение, затем обратный перенос улучшенных форм в Новый свет, где они поражаются коэволюционно связанным вредным организмом - и перенос уже вредного организма в Старый свет с последующей эпифитотией.

На основе экспериментальных данных построена математическая модель онтогенеза Tuta absoluta в зависимости от температуры. Применение модели для оценочных прогнозов термоадаптации вредителя с использованием данных метеостанций показало возможность развития томатной моли в Московской области минимально в двух генерациях.

\section{Библиографический список}

1.Ахиезер Н.И. Лекции по теории аппроксимации. М. Наука, 1965. 407 с.

2.Тихомиров В.М. Некоторые вопросы теории приближений. М.: Наука. 1976. 304 с.

3.Корейчук Н.П. Экстремальные задачи теории приближения. М.: Наука, 1976. 320 с.

4.Корн Г., Корн Т. Справочник по математике (для научных работников и инженеров). М.: Наука, 1973. 832 с. 5.Wegorek W.Investigation of spring migration of the Colorado beetle (Leptinotarsa decemlineata Say) and possibilities of combating the insect. Ecol. Pol. Ser. A3. 1955. Pp. 217-271.

6.Джорданенго Ф., Венсан Ш., Алехин А. (ред.) Насекомые-вредители картофеля. Мировые песпективы биологии и управления (пер. с англ. Р.А. Багрова Ю.А. Виноградовой, под ред. Р.А. Багрова). М.: КМК, 2018. С. $32-33$.
7.Равашдех Ш.Х., Заец В.Г. Томатная минирующая моль - опасный карантинный вредитель томата // Защита и карантин растений. 2011. № 12. С. 35-37.

8.Перевертин К.А., Заец В.Г. Опаснейший карантинный вредитель // Картофель и овощи. 2016. № 1. С. $18-21$

9.Перевертин К.А. Некоторые фитосанитарные аспекты деградации почв агроландшафтов России в условиях климатических изменений // Национальный доклад «Глобальный климат и почвенный покров России: оценка рисков и эколого-экономических последствий деградации земель. Адаптивные системы и технологии рационального природопользования (сельское и лесное хозяйство)». М.: Почвенный институт имени В.В. Докучаева, 2018. С. 45-47.

10.Перевертин К.А., Сагитов А.О. от свекловичной нематоды к проблемам продовольственной безопасности // Российский паразитологический журнал. 2014. № 1. С. 109-112

\section{Об авторах \\ Перевертин Кирилл \\ Александрович, доктор биол. наук,} Центр паразитологии Института про-

блем экологии и эволюции имени А.Н. Северцова РАН, Почвенный институт имени В.В. Докучаева.

E-mail: perevertink@mail.ru

Леунов Владимир Иванович, доктор с. - х. наук, профессор, и.о декана факультета агрономии и биотехнологии, РГАУ-МСХА имени К.А.

Тимирязева. E-mail: vileunov@mail.ru

\section{Багров Роман Александрович,} канд. с. - х. наук, с.н.с. лаборатории селекции и иммунитета пасленовых культур, Всероссийский научно-исследовательский институт овощеводства - филиал ФГБНУ «Федеральный научный центр овощеводства».

E-mail: romanus81@mail.ru.

Васильев Тарас Аркадьевич, Н.C. междисциплинарной лаборатории математического моделирования почвенных систем. Почвенный институт им. В.В. Докучаева.

E-mail: soilsystemslab@gmail.com

The ping-pong effect of transatlantic

bioinvasions (on the example of the

South American tomato moth)

K.A. Perevertin, DSc, Parasitology Centre,

A.N. Severtsov Institute of Ecology and

Evolution, Soil Institute named after V.V.

Dokuchaev. E-mail: perevertink@mail.ru

V.I. Leunov, DSc., professor, acting dean

of faculty of agronomy and biotechnology,

RSAU-MTAA. E-mail: vileunov@mail.ru

R.A. Bagrov, $P h D$, senior research fellow

of laboratory of breeding and immunity of solanaceous crops, ARRIVG-branch of

FCVG. E-mail: romanus81@mail.ru

T.A. Vasilyev, research fellow,

Interdisciplinary Laboratory for

Mathematical Modeling of Soil Systems,

Soil Science Institute named after V.V.

Dokuchaev.

E-mail: soilsystemslab@gmail.com

Summary. The phenomenon of Columbian exchange which began about 500 years ago, is far from over, as it is evidenced by the epiphytosis occurring in Eurasia, caused by harmful organisms of American origin. The aim of the study is to analyze the patterns of Intercontinental invasions of harmful organisms, including the South American tomato moth. The studies used standard methods of monitoring phytophagous insects, the method of approximation according to experimental data of the ontogenesis of moth stages depending on the temperature in vegetation and climatic cabinets. Information on the distribution of the South American tomato moth in the Old World is presented, theoretical aspects of the development of Intercontinental invasions are discussed, the phases of the evolution of the host-parasite relationship (background, latent, intensive, the phenomenon of Intercontinental stress-bioinvasion) are highlighted. Examples of Intercontinental bioinvasions of harmful organisms determining socially significant epiphytotic consequences (outbreaks of mass reproduction/ development) are given. Thermic aspects of the ontogenesis of tomato leaf miner moth are presented. On the basis of experimental data, a mathematical model of Tuta absoluta ontogenesis as a function of temperature is constructed. Application of the model for estimated forecasts of pest thermal adaptation using data from weather stations showed the possibility of tomato moth development in the Moscow region in at least two generations. An example of the cartogram of the forecast of the number of Tuta absoluta generations for the Moscow region is given. According to the results of the evaluation modeling (using the data of district weather stations for 2017) in the zone of the greatest risk of acclimatization of the harmful organism were Kolomna and Kashira districts. The information on the lower thermal limits of acclimatization of quarantine bioinvasions objects for the Russian Federation is given. We have definited he mechanism of transatlantic bioinvasions as a "ping-pong effect". This phenomenon of inversion multiplicity of Intercontinental bioinvasions within the framework of the Columbian exchange describes Tuta absoluta bioinvasion, a direct analogy of which is the transatlantic epiphytosis of potato globoderosis. The scheme is as follows: the transfer of the host plant from the New world to the Old world, his selective improvement, then an improved reverse transfer forms to the New world, where they marvel at the co-evolution connected with harmful organism and the transfer of already a pest in the Old world with subsequent epidemics.

Keywords: Tuta absoluta, Columbian exchange, ontogenesis, mathematical model, thermal adaptation, cartogram.

№12/2019 Картофель и овощи 